\title{
Study on Karst Rock Desertification by Human-Nature Interaction: A Case Study of Fengshan County of Guangxi, China
}

\author{
Guoqing Zhou*, Chengjie Su, Rongting Zhang, Yujun Shi, Yilong Liu, Yundong Ma \\ GuangXi Key Laboratory for Spatial Information and Geomatics, Guillin University of Technology \\ Guilin, GuangXi, 541004, China
}

KEY WORDS: Remote sensing, Rocky desertification, Human activity, Fengshan

\begin{abstract}
:
Rocky desertification is a process of soil erosion leading to the bareness of bedrock, and is a kind of typical natural disaster in karst areas, which seriously constrains the developments of local society and economy. This paper studies the impact of human activities on the changes of rocky desertification. With the interpretation of remote sensing images of Fengshan County, GuangXi, China covering 1990, 1995 and 2005, this paper analyzes the relationship of the changes of social and economic index (including population density, agricultural population, rural per capital net income, and farmland) and the changes of rocky desertification in recent 15 years. The results indicate that: in recent 15 years, the average annual growth rate of rocky desertification, rate of change of population density, agricultural population, rural per capita net income, and farmland area are $8.7375 \mathrm{~km}^{2} /$ year, 0.7 person $/ \mathrm{km}^{2}$. year, 1153 person/year, 85 Yuan/year, and -269.1 ha/year, respectively. The first three of social and economic indicators at different degrees of growth, show a positive correlation with rocky desertification change. However, farmland area, which has been diminishing, shows a negative correlation with rocky desertification. The influence of human activities for karst rocky desertification can be regarded as population growth - steep slope reclamation - the destruction of vegetation - erosion - rocky desertification poverty.
\end{abstract}

\section{INTRODUCTION}

Karst rocky desertification is recognized as a new type of geo-ecological disaster, which impacts the economy, environment and society strongly, and is significantly concerned by government at different levels in recent years $(\mathrm{Li}, 2004 \mathrm{a})$. Karst rocky desertification is a vagary geographical process in karst region, and is also a product of unbalanced development of man-natural interactive system. This means that the karst rocky desertification is a combined product under the influence of geology, topography, climate, soil, and vegetation and other natural background factors and irrational human activities. Human activities have a greater effect on the environment karst region (Hudson, 2006a). Rocky desertification is a typical geological environmental disaster of karst areas, resulting in the loss of land, a lot of exposed bedrock and serious impact on land use, which is particularly serious in tropical karst mountain for plenty of rainfall (Smith, 1988a; Templer, 2005a).

The research on the karst rocky dissertation has been studied over the past decades. Wang (2004) and Li (2009a) employed land use and land cover to extract the rocky desertification. Li (2003a) discussed the relevance between various types of rock and different levels of rocky desertification, and demonstrated that pure carbonate rocks have a significant correlation to rocky desertification. Yang (2009a) discussed the geological and geomorphological factors affecting the distribution of rocky desertification. The result showed that the occurrence of rocky desertification in different landform zones from high to bottom is high cluster-peak depression zone, moderate cluster-peak depression zone, peak-cluster valley zone, hilly zone. Hu (2006a) and Bai (2006a) presented relationship between rocky desertification and human activities. Xiao (2007a) studied the surface temperature in the karst areas of land use changes. Xiong (2009a) quantitative explored the driving force of rocky desertification, which is calculated dissolution amount of carbonate rocks by different year temperatures and rainfall in karst area.

This paper uses the data covering 1990 through 2005 to find out the relationship between human driving forces and rocky desertification, including population density, agricultural population, rural per capital net income, and farmland in the past 15 years in Fengshan County, GuangXi, China.

\section{STUDY AREA AND DATA SET}

\subsection{Study area}

Fengshan (Figure 1) is located in the northwest of Guangxi Zhuang Autonomous Region, at latitude $24^{\circ} 15^{\prime}$ through $24^{\circ} 50^{\prime} \mathrm{N}$, longitude $106^{\circ} 41^{\prime}$ through $107^{\circ} 17^{\prime} \mathrm{E}$. The study area is belonged to subtropical monsoon climate, which have an abundant rainfall and adequate light. The average annual temperature is $20.1^{\circ} \mathrm{C}$, and annual rainfall is $1564.0 \mathrm{~mm} /$ year.

\footnotetext{
* Corresponding author: Guoqing Zhou; Tel. /Fax: +86(773)5896073;

E-mail: gzhou @glut.edu.cn.
} 


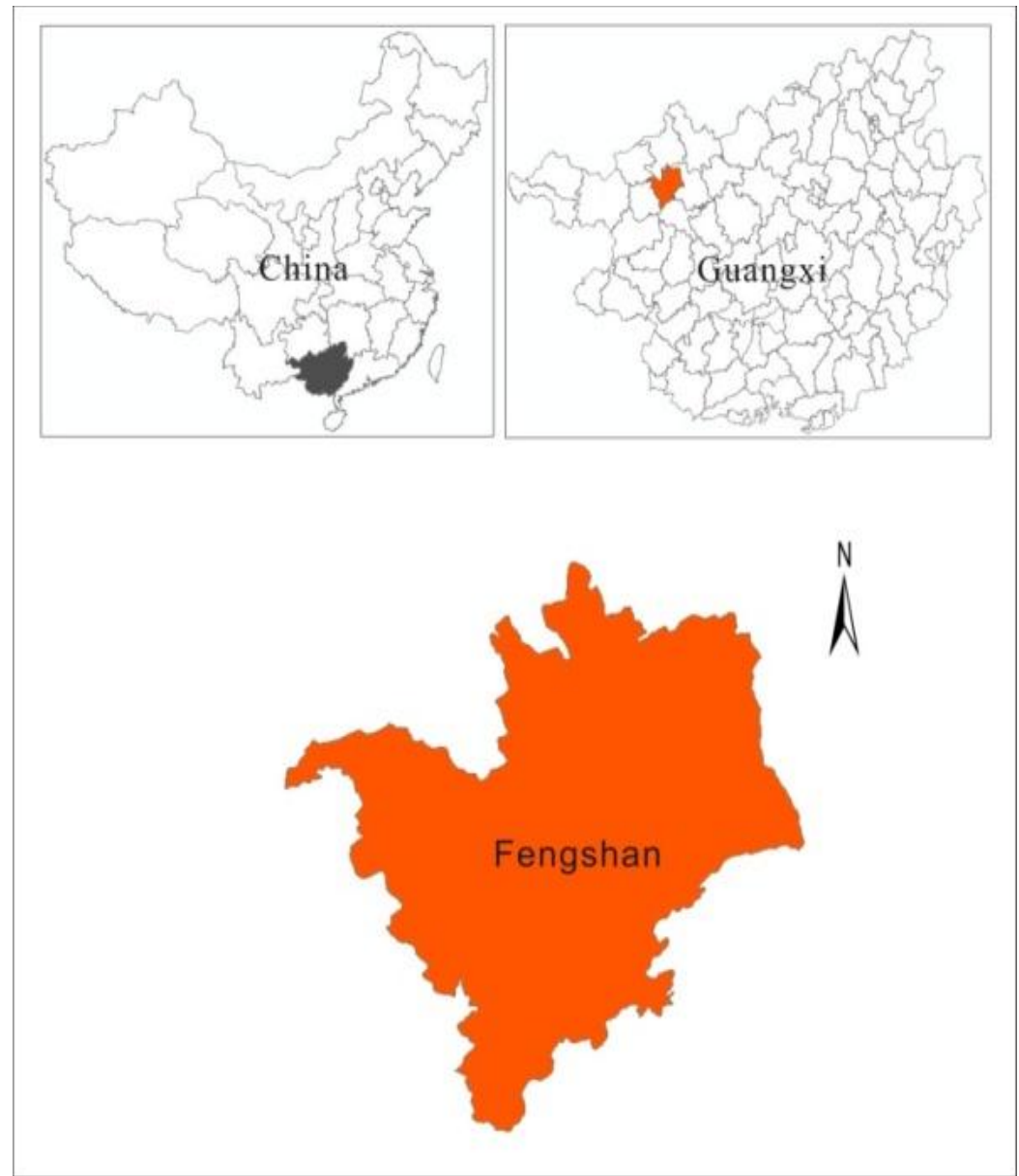

Figure 1. Location map of Fengshan County, GuangXi, China

\subsection{Data Set}

These remote sensing images used in this paper are downloaded from Computer Network Information Center, Chinese Academy of International Scientific data mirror sites at http://www.gscloud.cn. The downloaded data include Landsat-5 TM images with cloudiness of less than $10 \%$ in 1990, 1995 and 2005. The Fengshan socio-economic index data covering 15 years are downloaded from Guangxi geography web page at http://www.gxdqw.com/. The socio-economic data included total 15 year population, rural per capita net income and farmland.

\section{RESEARCH METHODS}

\subsection{Research methods}

The workflow of study method is shown in Figure 2. First, remote sensing images are downloaded and tailored by the region of Fengshan administrative, and then combined to from false color composites (RGB: band 5, 4, 3) using ENVI 4.8 software. Second, the false color image features at different rocky desertification are determined using GPS in field. Meanwhile, the results through analyzing vegetation coverage and terrain slope are used to determine the index of classification of rocky desertification in the study area, as presented in Table 1. The index of classification interpret the remote sensing of Fengshan by decision tree (Hansen, 1996a; Mahesh, 2003a), thus rocky desertification can be obtained the spatial distribution of different three years. Finally, nearly 15 years socio-economic index data of Fengshan are collected and used to make an analysis to attempt to discover the relationship between changes of socio-economic and rocky desertification.

Table 1. Fengshan rocky desertification classification index

\begin{tabular}{cccc}
\hline $\begin{array}{c}\text { Rocky } \\
\text { desertification } \\
\text { rating }\end{array}$ & NDVI & $\begin{array}{c}\text { Vegetation } \\
\text { coverage }(\%)\end{array}$ & Slope $\left({ }^{\circ}\right)$ \\
\hline Non & $>0.32$ & $>65$ & $<19$ \\
Potentially & $0.15 \sim 0.32$ & $50 \sim 65$ & $>19$ \\
Mild & $-0.05 \sim 0.15$ & $30 \sim 50$ & $>24$ \\
Moderate & $-0.27 \sim-0.05$ & $20 \sim 30$ & $>28$ \\
Strength & $-0.48 \sim-0.27$ & $9 \sim 20$ & $>35$ \\
Extremely & $<-0.48$ & $<9$ & $>45$ \\
\hline
\end{tabular}




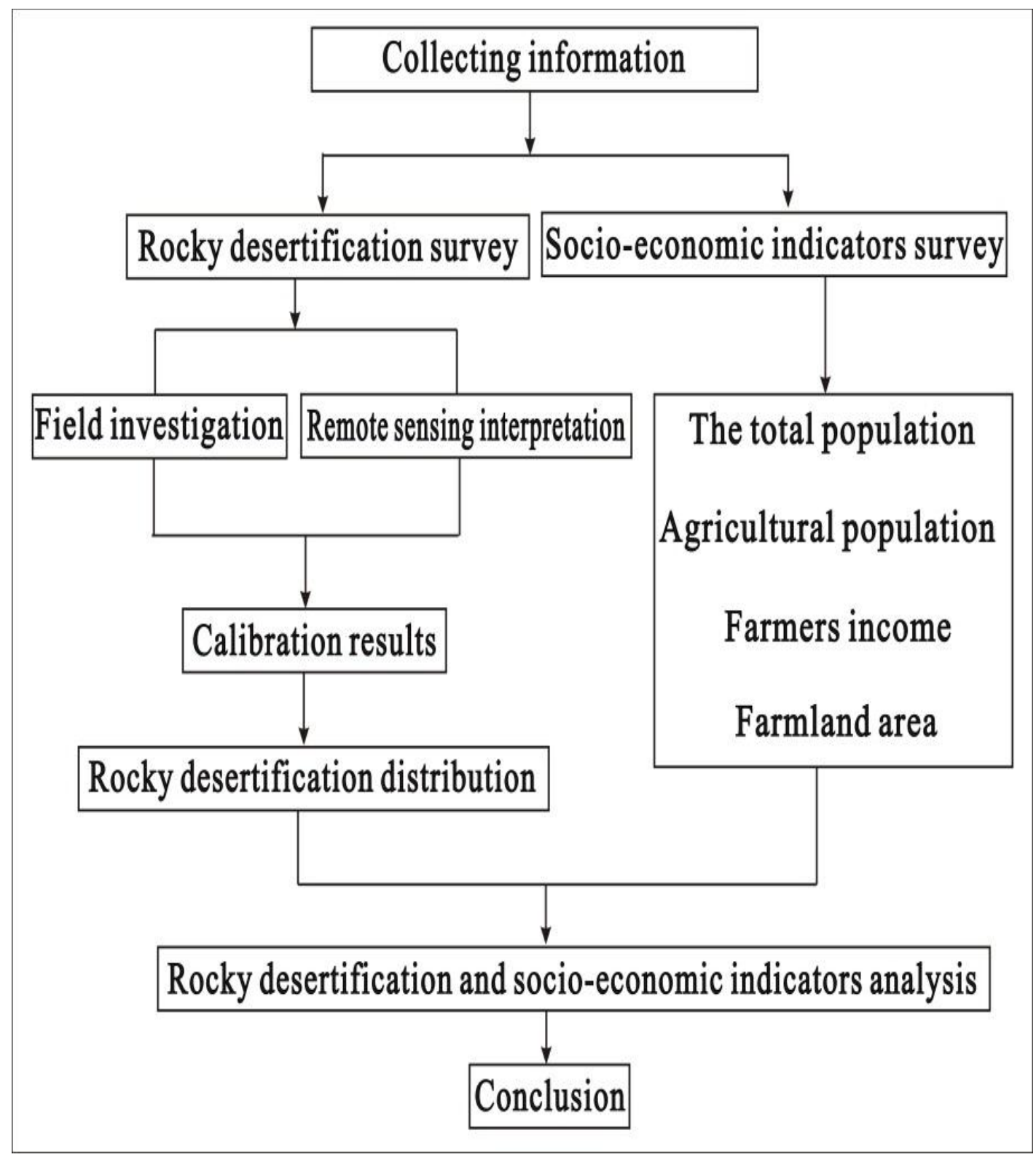

Figure 2. The flowchart of study method

\subsection{Classification results}

The rocky desertification spatial distribution of Fengshan obtained by using the methods proposed in Figure 2 is shown in Figure 3. With the statistical analysis, the line chart of rocky desertification of Fengshan in three different years is depicted in Figure 4. Table 2 shows that each levels rocky desertification increased at year-by-year and rocky desertification area is being expanded gradually. As observed in Figure 4, the increment of rocky desertification area is $25.65 \mathrm{~km}^{2}$ from 1995 to 2005 , and the increment of rocky desertification area is $105.41 \mathrm{~km}^{2}$. Average annual growth rate is about $8.74 \mathrm{~km}^{2} /$ year. 


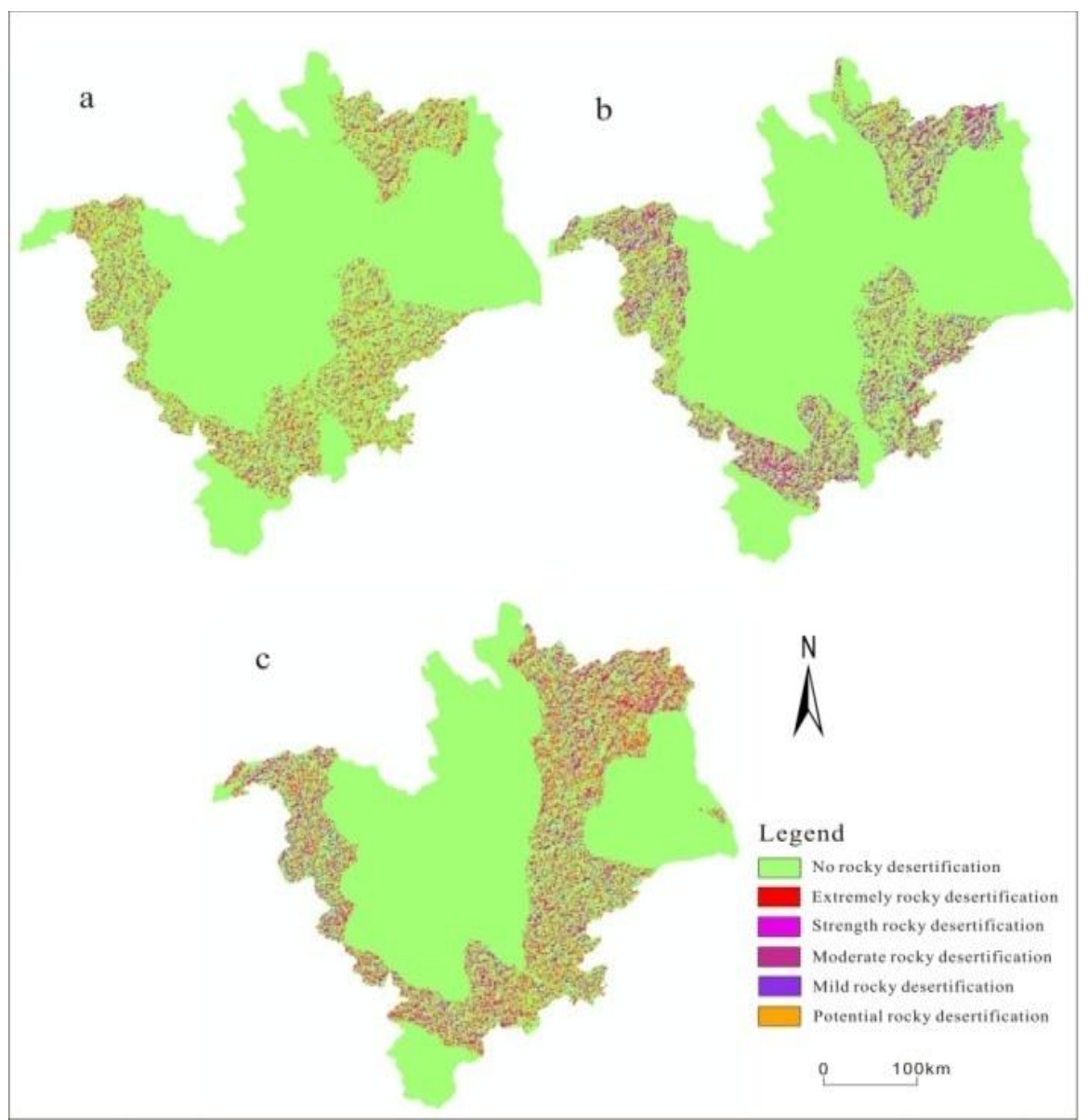

Figure 3. (a), (b), and (c) represent the rocky desertification spatial distribution of Fengshan in 1990, 1995 and 2005, respectively.

Table 2. Rocky desertification statistical results

\begin{tabular}{ccccccc}
\hline Year & Extremely & Strength & Moderate & Mild & Potentially & Non \\
\hline $1990\left(\mathrm{~km}^{2}\right)$ & 12.61 & 20.37 & 42.89 & 23.21 & 100.73 & 1542.95 \\
$1995\left(\mathrm{~km}^{2}\right)$ & 19.53 & 44.14 & 43.23 & 59.89 & 58.67 & 1515.89 \\
$2005\left(\mathrm{~km}^{2}\right)$ & 14.01 & 48.05 & 87.83 & 49.30 & 131.68 & 1411.82 \\
\hline
\end{tabular}

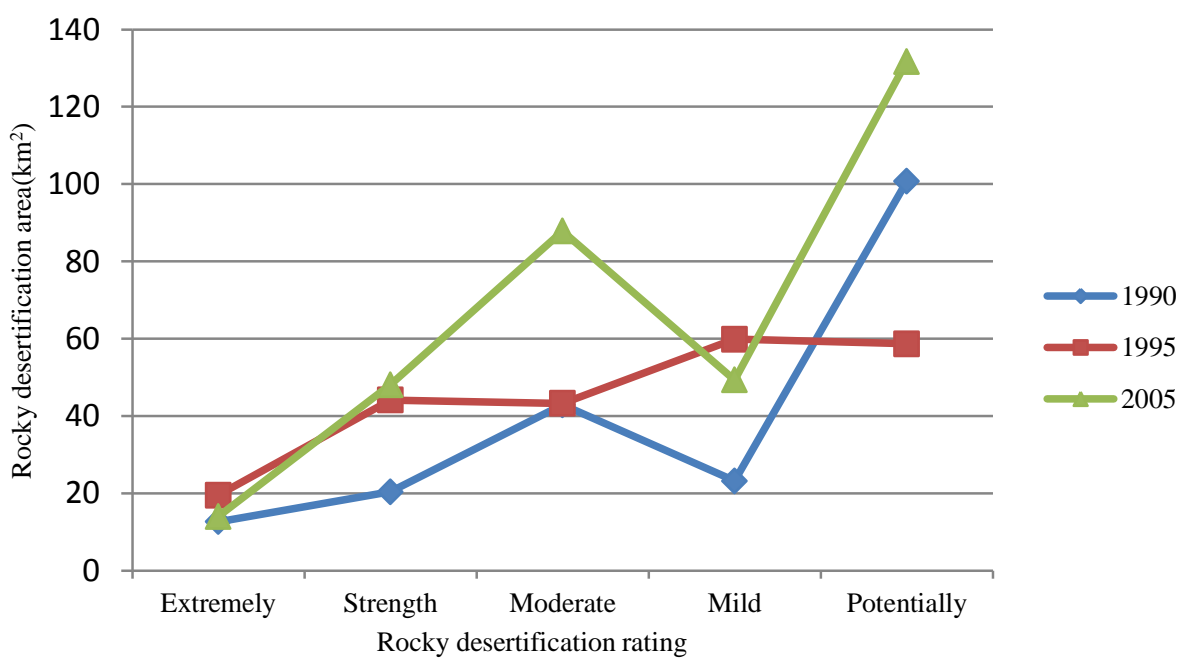

Figure 4. Three different year rocky desertification of Fengshan County, GuangXi, China 


\section{RELATIONSHIP BETWEEN ROCKY DESERTIFICATION AND SOCIAL ECONOMIC INDEX}

Four social and economic index of nearly 15 year were filtrated, including population, agricultural population, rural per capita net income and the farmland area are employed to research the relationship between them and the karst rocky dissertation. Population density is the values of residents who are living within a unit land area $\left(1 \mathrm{~km}^{2}\right)$. Population density is calculated by total population divided by the total land area. This index reflects the degree of regional population dispersion. Over the recent 15 years, the population density, agricultural population and rural per capita net income in the Fengshan County increase at an annual base, while agricultural acreage is opposite.

Taking the natural background as the internal cause of rocky desertification, the unreasonable human activity is the external cause. In the condition of no human activity or week effect of human activity, rocky desertification will also develop and evolve continuously under the drive of internal cause. But the change is slow, which belong to the normal phenomena of nature. In the specific karst environment background, due to unreasonable human activities, there is a significant change of the speed of rocky desertification. At a certain scale, unreasonable human activity is the main reason of the change of the karst rocky desertification. Specifically, rocky desertification is caused by the interaction of human activities and vulnerability of the ecological environment due to natural background. The influence of human activities, including the production and living activities, on rocky desertification can be divided into direct effect and indirect effects.

The changes of rocky desertification and social-economic index of Fengshan in recent 15 years are show as Table 3. As observed in Table 3, rocky desertification, population density, agricultural population and the per capita net income of farmers increase and have a positive correlation with the change of rocky desertification; agricultural acreage has a negative correlation with the change of rocky desertification.

Table 3. Rocky desertification and socio-economic index changes in Fengshan County, GuangXi, China

\begin{tabular}{cccc}
\hline & 1990 & 2005 & Annual growth \\
\hline The population density (person/ $/ \mathrm{km}^{2}$ ) & 97 & 108 & 0.73 \\
Agricultural population (Million) & 15.57 & 17.3 & 0.1153 \\
Rural per capita net income (Yuan) & 234 & 1510 & 85.07 \\
Farmland area (Million ha) & 1.01 & 0.61 & -0.02691 \\
Rocky desertification area $\left(\mathrm{km}^{2}\right)$ & 199.81 & 330.87 & 8.74 \\
\hline
\end{tabular}

\section{CONCLUSIONS}

According to the above results and analysis, it can be concluded that

(1) The total areas of rocky desertification of Fengshan are $199.81 \mathrm{~km}^{2}, 255.46 \mathrm{~km}^{2}$ and $330.87 \mathrm{~km}^{2}$ in 1990,1995 and 2005 , respectively. The rate of change of rocky desertification in recent past 15 years is about 8.74 $\mathrm{km}^{2} /$ year.

(2) The change rate of population density, agricultural population, rural per capita net income, and farmland area, in nearly 15 years in Fengshan, are about 0.7 person $/ \mathrm{km}^{2}$.year, 1153 persons/year, 85 Yuan/year and $-269.1 \mathrm{ha} /$ year, respectively. The first three values with different degrees of growth show a positive correlation with rocky desertification change. However, farmland area, which is diminishing, showed a negative correlation with rocky desertification.

\section{ACKNOWLEDGEMENTS}

This paper is financially supported by China Nature Science Foundation under contract number 41162011, Guangxi Governor Grant under approval number of 2010-169, Guangxi Grand Natural Science Foundation under the number of 2011GXNSFD018001 and 2012GXNSFCB053005, Guangxi Key Laboratory of Spatial Information and Geomatics under approval number of 130511401.

\section{REFERENCES}

Bai, X. Y., Xiong, K. N., Li, Y. B., et al, 2006a. Quantitative research of the space dependence of different grades rocky desertification and the factor of population in karst mountain area. Journal of Mountain Science, 24(2), pp. 242-248.

Hu, B. Q., Jiang, S. F., Liao, C. M., et al, 2006a. TUPU analysis on driving mechanism of Guangxi karst rocky desertification based on 3S techniques. Journal of Mountain Science, 24(2), pp. 234-241.

Hansen M, Dubayah R and Defires R, 1996a. Classification trees, an alternative traditional land cover classifiers. International Journal of Remote Sensing, 17, pp. 1075-1081.

Hudson, P. F and Alcantara-Ayala, I., 2006a. Ancient and modern perspectives on land degradation. Catena, 65.

Li, Y. B., Shao, J. G., Yang, H., Bai, X. Y., 2009a. The relations between land use and karst rocky desertification in a typical karst area, China. Environment Geomorphology, 57, pp. 621-627.

Li, R. L., Wang, S. J., Zhou, D. Q., 2003a. The Correlation between rocky desertification and lithology in karst area of Guizhou. Geographical Journal, 58(2), pp. 314-320.

Li, Y. B., Wang, S. J., and Li, R., 2004a. Discussion of karst rocky desertification desert and concepts. Chinese Desert, 24(6), pp. 689-695. 
Mahesh, Pal and Paul, M., 2003a. An assessment of the effectiveness of decision tree methods for land cover classification. Remote Sensing of Environment, 86, pp. 554-565.

Smith, B. J, 1988a. Weathering of superficial limestone debrisin a hot desert. Environment Geomorphology, 1(4), pp. 355-367.

Templer, P. H., Groffman, P. M., Flecker, A. S., 2005a. Land use change and soil nutrient transformations in the Los Haitises region of the Dominican republic. Soil Biology and Biochemistry, 37(2), pp. 215-225.

Wang, S. J., Liu, Q. M., Zhang, D. F., 2003a. Karst rocky desertification in Southwestern China, geomorphology, land use, impact and rehabilitation. Land Degradation \& Development, 15, pp. 115-121.

Yang, Q. Q., Wang, K. L., Chen, H. S., 2009a. Effects of geology and landform on karst rocky desertification: a case study in Dahua county of Guangxi, China. Journal of Mountain Science, 27(3), pp. 311-318. 